
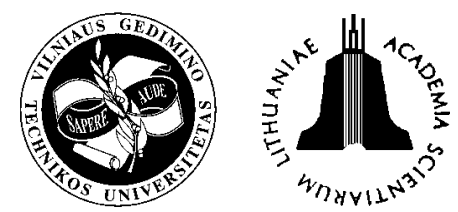

ISSN 1648-4142 print/ ISSN 1648-3480 online TRANSPORT

www.transport.vtu.lt

\title{
THE EVALUATION OF TRANSIT TRANSPORT PROBABLE EFFECTS ON THE DEVELOPMENT OF COUNTRY'S ECONOMY
}

\author{
Michail Litvinenko', Ramūnas Palšaitis² \\ Department of Transport Management, Vilnius Gediminas Technical University, \\ Plytinès g. 27, LT-10105 Vilnius, Lithuania. Tel.: +370 52744776 \\ ${ }^{1}$ E-mail: michaill@mail.lt, ${ }^{2} E$-mail:trvadyba@ti.vtu.lt \\ Received: 8 December 2005; accepted: 28 March 2006
}

\begin{abstract}
The article describes the peculiarities of transit transport influence on the development of country's economy. The authors analyze transit transport definition and define the economic importance of transit transport. The first part of the article is assigned to the consideration of transit cargo transportation as an integral object of scientific research. The survey is supported with the comparative analysis of different scientists' approaches to the transit transportation performance modelling. The evaluation of transit transport benefit for the economy of the country is presented. The concise summary of a principal thesis and conclusions may be useful for further analyses of different aspects or transit transport.
\end{abstract}

Keywords: transport, service, transit, flows, profit.

\section{Introduction}

The Lithuanian geopolitical state and well-developed transportation infrastructure provide a possibility not to remain in the background of current changes in the transit services market, but to act as a mediator in the expansion of trade connections of the most important transportation corridors between East and West.

It can be stated that the development of transit is one of the most important areas in the transportation system of the country today.

The changes, which are taking place in the international transit services market, demand not only the modernization of the current infrastructure, by releasing intended development projects, but also the application of modern transportation and applied information technologies. Through time this will secure the competitive ability of the country in the international transit services market, as well as speed up the possibilities of integration into the European Union's economic space. Once again it proves that the development of transit transportation must become one of the underlying objectives of the economy of the country.

\section{Conceptual considerations}

The infrastructure of transit comprises all the institutions and organizations, which in one way or another are directly related to transit or its development. The elements of the transit system are:

- transit goods transportation: by roads, by rail, by water, by air and by pipelines;

- transit infrastructure: primary - roads, railroads, harbours, terminals, where cargo shipment is carried out, transport logistics centers, banks, insurance companies, shipping companies, etc.;

- wayside infrastructure: gas-stations; road vehicle technical supervision and repair stations; hotels, motels, restaurants, cafes and other transit transport service objects.

Transit is perceived as the transportation of goods through other countries. Thus, it can be a premise and an aim for expansion and development, an object for scientific research and an area for logistic projection and collaboration.

The main problem of transit transportation is the attraction of transit cargo flows. Whenever various transportation means are exploited in transit transportation, various modes of transport, i.e. the whole transportation system, is in operation.

The interplay of transport modes carrying a transit cargo is one of the pivotal problems of transit transportation. So, it is important to evaluate the experience of foreign countries whilst analyzing combined transportation as an object of research. The research object of the interplay problem has been analyzed for 
several decades already; however, the conceptualization process is still continuing.

The selection of terminals and the choice of the place of cargo transshipment are important factors in dealing with transit routing issues. For this reason many authors separate terminals to a special group as a nodal point where a vehicle of one type is exchanged with a vehicle of the other [1,2].

In 1991 the EU adopted a resolution titled "European Agreement on Important International Combined Transport Lines and Related Installations (AGTC)". The main objective of this resolution was to develop the appropriate infrastructure quality standards in the primary European transportation corridors. The core of this resolution is that combined transport works according to the principle "from door to door" and is only as strong as its weakest link. Even if the smallest part of the corridor causes trouble in the process of combined transportation, all efforts to improve the quality of transportation in this corridor can be fruitless.

These requirements have influence on the formation of combined transport strategy aims of all European countries regulating them on the international level. Since a transportation corridor, through which international transportations are pursued, stretches through the territories of several countries, all the countries have to care for the AGTC requirements implemented on their territory. In this case attracting of financial means for the development of transportation corridors modernization projects becomes an important criterion. The introduction of common standards in combined transportation corridors is quite relevant seeking to secure desirable transportation quality.

Some scientists define transportation quality as a final result of the transportation service. This result includes not only the transportation of passengers or cargo, but also the whole range of additional functions provided for the consumer using a vehicle or a terminal. Service quality is expressed as a general effect of the services provided, which demonstrates the level of consumers' service.

Using this method for the analysis of service quality, the factors that determine the services as well as their influence on the quality of these services are evaluated. This evaluation causes premises to be theoretically based on the modelling of the transportation flow. In order to use modelling effectively, the conditions that are securing a connection between incoming and outgoing elements of the same system need to be formed [3]. This is important in striving for the desired result and introducing appropriate amendments.

Considering transportation modelling principles, transit transportation began to be investigated after the evaluation of the external macro- and micro-environmental criteria, which influence them. In this case microenvironment is defined by the factors having a direct influence on the enterprise and its possibilities to serve consumers. Macroenvironment is defined by factors that embrace a markedly wider range of criteria and influence the microenvironment. In each of these environments a range of factors function, the examination of which embraces the evaluation of many areas including the preparation of methodology.

G. Pavone [4] offers to evaluate the quality result of the transportation interplay as service and the final product. The model he offers is based on the difference between demands and possibilities. This model considers a fundamental link between an order placement and a service, which depend upon the technical factors conditioned by the available material possibilities. G. Pavone refers to the external factors as to the ones identifying the quality of services from the consumer's point of view; whereas he relates internal factors to the supply of technical and technological services.

Almost all projects dealing with transportation have to keep in mind environmental issues regarding air and environmental pollution, noise, oscillation, etc. So, special consideration is given to combine transit cargo transportation to help to create a prevention programme for the reduction of transportation pollutants. Consequently, a great many scientists relate transit transportation development to the reduction of traffic jams and environmental protection.

The interplay between separate factors in the microenvironment is analyzed from different aspects, usually in accordance with microeconomics. According to transportation management and transit technology the most important issues are related to the selection of the driver and the mode of transport, informational technologies, management and control. Financial issues are a separate unit, i.e. transportation costs and price formation and profitability of the enterprise activity.

While the scientists are paying not enough attention to the development of transit combined transportation in conjunction with modern logistics solutions, little attention is also paid to the analysis of combined transportation concept itself. In addition, transit combined transportation is analyzed as a whole without considering the peculiarities of the transportation modes involved. Consequently, the superficial analysis does not allow comprehensive conclusions to be drawn in the final result or the optimal result to be striven for.

In order to fully identify the interplay of railroads and sea transport in carrying transit cargo through 
Lithuania, both macroeconomics and microeconomics theses examined by scientists are referred to. Various simplifications are widely invoked in the economic analysis: no regard is paid to the differences amongst the country's population as consumers, amongst the multitude of enterprises, goods produced, etc. [5, 6] Economic models allow the separation of nonessential factors and clarification of principal economic connections. K. E. Case and C. R. Fair [7] define an economic model as a simplified theory that describes how concrete factors effect on the economy.

External factors define initial information and function until the model is operating; whereas internal ones form the inside of the model and are the result of its activity.

The principles mentioned are very important for the process of making a transit transportation model as well as for distinguishing the factors, which influence this model. External (macroenvironmental) and internal (microenvironmental) identification simplifies the analysis of the effect of the factors and permits clear identification of the tasks and results.

Creating a transit transportation model in the context of planning strategic cargo flows on a national or regional scale; the transportation infrastructure is used more effectively when cargo is transported with the minimum common costs [8]. Even if the premise is invoked that certain conditions do not precisely allow the cargo to be sent with the minimum costs, this premise is also valid when the model formed is based on the aim of the reduction of common costs.

The joint transportation selection model suggested by R. G. Kasilingam [9] proposes cost reduction as an objective. Also, there are models which raise the hypothesis that trans-regional flows of goods are sensitive to supply factors such as manufacturing costs in the place of origin, transportation costs from the place of origin to the destination point, as well as to demand factors such as revenue at the destination and price fixing, which is set for the goods of the competitive markets.

For a long time the researchers of combined transportation have been emphasizing service costs and price as the main determinant factors which condition cargo transportation. However, there is another point of view [10], which evaluates factors and their categories influencing cargo transportation, i.e. factors related to the cargo flows, cargo characteristics and customer service.

It is necessary to emphasize that the tendency to single out the factors related to customer service (speed, flexibility, accessibility), organizational needs (amount of orders), cargo features (amount, weight, container) is becoming more apparent and this determines the application of the marketing theory to the general cargo transportation process in order to meet the needs of customers.

Many authors hold the opinion that the aim of transportation interplay is to choose an optimal cargo transportation variant by combining the advantages of separate transportation types. Though this attitude reveals only a part of the truth, since it does not reflect all the requirements set for combined transit transportation and does not meet the demand of consumers. Therefore, other transportation aims occur such as "from door to door" transportation, provision of quality services based on competitive prices, and etc.

Every country encourages transit transportation possibilities through its territory by convenient geographical locations and a proper infrastructure. In order to form beneficial conditions for transit cargo transportation through the territory of Lithuania, it is essential that the whole transit transportation system functions well.

Transit cargo transportation will provide the Lithuanian transportation enterprises with the opportunity to increase their scope of services. This would be beneficial for Lithuania according to the following main aspects:

- the state budget will receive more revenue by means of different taxes;

- the received additional incomes will allow updating the transportation system making it more effective and competitive in the international market;

- increased business will be guaranteed in the transportation sector.

Transit cargo transportation through the Lithuanian territory would have an indirect economic value, i.e. service needs of transit transportation flows would create a demand in the sphere of trade and services. This would help to solve business problems and be particularly relevant in Lithuania's peripheral regions where neither manufacture nor trade is active. Possibilities for the implementation of new transportation technologies and goods delivery by modern organizational methods would increase. In order to realise the stimulation objectives of the transit trade, it is necessary to form a technically, technologically, organizationally and legislatively attractive activity environment securing a reliable and safe service of transit flows [11, 12].

In order to improve the competitive position of Lithuania in the Baltic region, greater importance should be given to the general organization of transit transportation. Moreover, in order to develop intermodal and joint transportation successfully, the railroads, roads and harbour infrastructure must be improved [13]. 
Whether transit cargo flows will go through the Lithuania and not through the alternative routes using the territory of neighbouring countries depends upon the conditions the Lithuanian transportation system will provide for senders and receivers of this cargo.

Therefore, the Lithuanian transportation system must be transformed so that both its technical conditions and its regulating legislative base would be acceptable for the economic agents implementing transit. Consequently, during the arrangement of transit strategy principles it is necessary first to propose a common transit policy and on its basis to organise transit activity in the country not excepting separate institutions, particularly the state supervisory ones. Sometimes efforts by a separate company to attract cargo flows are "swept" by one decision of the state institutions or by the order of a separate bureaucrat.

Transit systems should be clear, simple, easily administered and as stable as possible in all cases.

\section{Evaluation of the transit benefit for the economy of the country}

The revenue from transit transport in the form of various taxes (direct taxes on transit, customs, police escort, fees for the use of the infrastructure) gets into the state budget and together stimulates economic development of the country. Total annual direct revenue from the transit can be calculated as follows:

$$
\begin{aligned}
& \text { Ptr(direct })_{y}=T(\text { vet })_{y}+T(\text { cust })_{y}+T(\text { storage })_{y}+ \\
& T(\text { road })_{y}+T(\text { mob. object })_{y}+T(\text { security })_{y}
\end{aligned}
$$

here: $T(\text { cust })_{y}$-annual revenue of customs terminal (shore term), Lt;

$T$ (storage $)_{y}$ - annual revenue of cargo storage services, Lt;

$T(v e t)_{y}$ - annual revenue from veterinary, fitosanitary and other inspections Lt;

$T(\text { road })_{y}$ - annual revenue of road users, $\mathrm{Lt}$;

$T(m o b \text {. object })_{y}$ - annual revenue of environmental pollution from mobile pollution objects, Lt;

$T$ (security $)_{y}$ - annual revenue from transit road transport convoy, Lt.

State receives the biggest revenue from the customs terminals usage (Fig 1).

A great effect on the economy is made not only by a directly received income invoked by the transit transportation flow going through Lithuania, but also by other sources like the income received from goods and services sold.

$$
\begin{aligned}
& \operatorname{Ptr}(\text { indirect })_{y}=I(\text { fluel })_{y}+I(\text { living })_{y}+ \\
& I(\text { service })_{y}+I(\text { pay })_{y},
\end{aligned}
$$

here: $I(f l u e l)_{y}$ - annual income of state budget for fuel taxes, $\mathrm{Lt}$;

I(living) $)_{y}$ - annual income of state budget for expenses of drivers living in Lithuania, Lt;

I(service $)_{y}$ - annual income of state budget for technical service of transit transport, Lt;

$I(\text { pay })_{y}$ - annual income of state budget from drivers income taxes, $\mathrm{Lt}$.

The fact to be kept in mind is that service is needed for transit transportation flows to go through the territory of the state. Consequently, a demand is created both in trade and services spheres. Moreover,

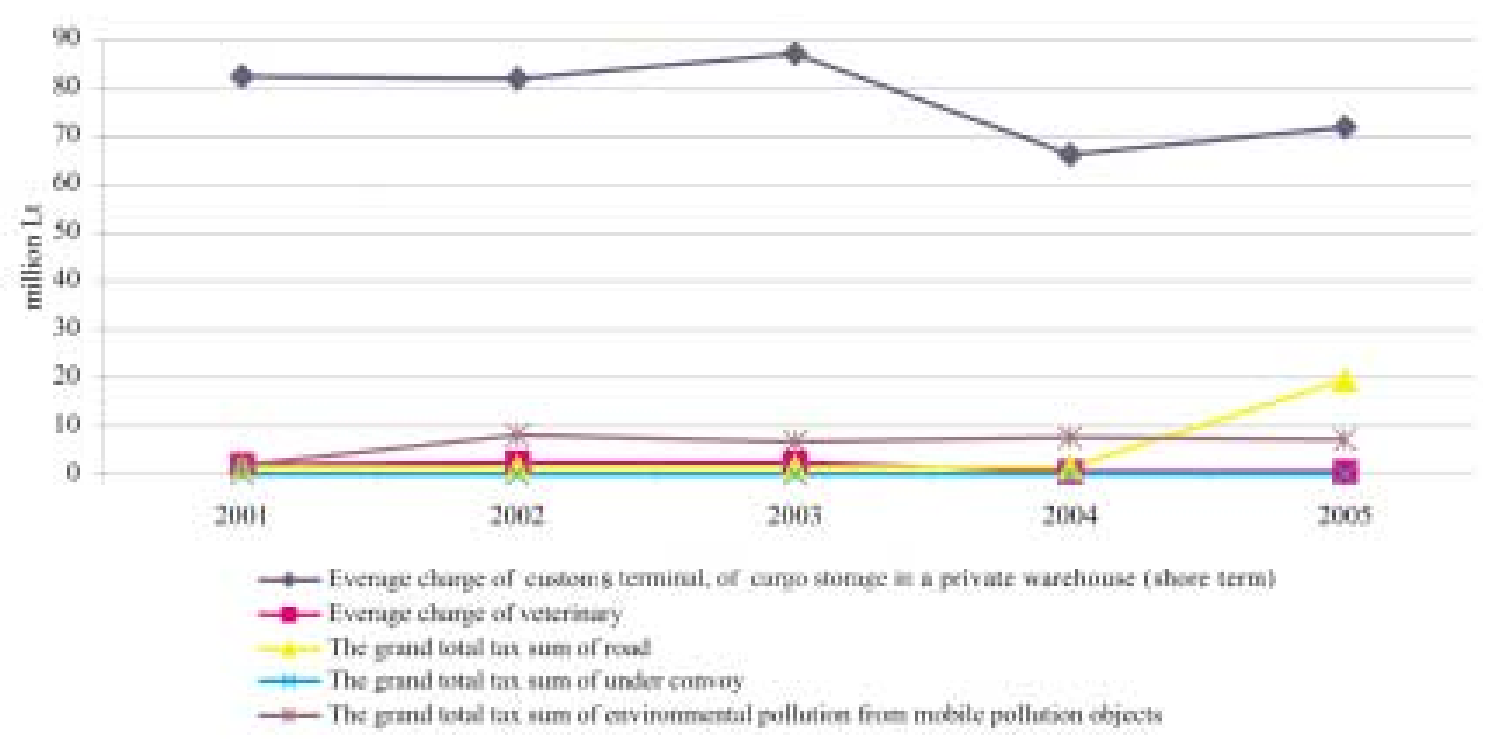

Fig 1. Evaluation of the transit benefit (of various taxes) for the economy of the country 
private initiative directed to the demand satisfaction is stimulated.

On the basis of this, a premise can be made that with the help of transit transportation new additional work places could be established by increasing living standards and purchasing power of the working class. Internal trade and developing businesses would become more active, tax revenue would increase and unemployment would decline. Moreover, the average class of the society with fairly stable purchasing power could be established.

Transportation development influences greater mobility. Furthermore, a large proportion of commonly used goods can be distributed to consumers. Transportation in well-developed countries ranges from 8 to $10 \%$ of gross national product and makes up to $5 \%$ of work places. The efficiency of a transportation system of a country can be measured by the common social-economic value as well as by the negative effect (formula (3) caused by certain parts of the transportation system or by the system itself (Fig 2):

$$
D_{y}=D_{t r} r_{i j / y}+\text { Dtro }_{y}+\text { Dtrn }_{y}+\text { Dtra }_{y},
$$

here: $D t r_{i \rightarrow j / y}$ - infrastructure damage value, that the transit transport means make (road damage), Lt; Dtro $_{y}$ - the expenditures, which have more use than liquidation of the pollution of transit transport means, $\mathrm{Lt}$;

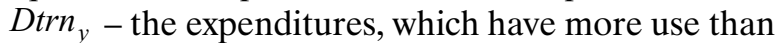
reduction of the noise of transit transport means, $\mathrm{Lt}$; Dtra $_{y}$ - losses value of transit transport traffic accidents, Lt.

Recently separate businessmen and firms have raised interest in alternative transportation system projects and their elements, the effect on the increase of the income of population, the creation of new work places, the economic increase of the analyzed region, population number and transportation mobility increase, changes in the settlement system and other potential changes. This phenomenon can be called a social-economic effect and it should be investigated in every possible way before the acceptance of the final transportation system development version or concrete projects, as well as the establishment of a scope of capital investment.

Until now the development of the transportation system has been related a little to the other components of the Lithuanian economic infrastructure. Usually it was limited to capital investment for the development of the transportation system up to the set period. At the state level the social-economic evaluation of the transportation system was not implemented due to the following reasons:

- models showing the social-economic effect in transportation are mostly adjusted to the establishment of the efficiency of concrete roads or transport objects, but not to the whole net of roads or the whole system;

- for the establishment of the efficiency of transportation systems the models evaluating convenience and service improvement for the external alternating changes (speed, increase of throughput, decline of social transportation weighting, waiting time, decline of transportation distance, etc.) were used;

- a modelling system, which evaluated long-lasting social-economic effects of the transportation sys-

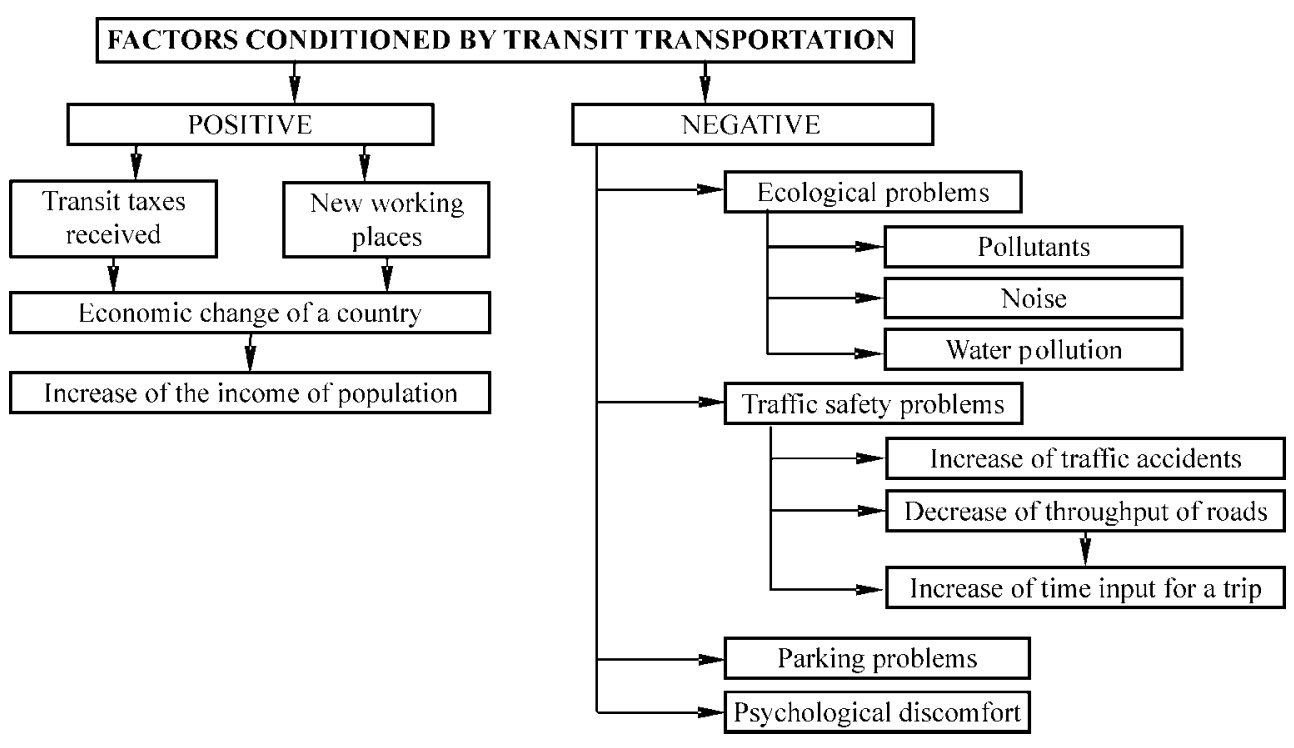

Fig 2. Factors conditioned by transit transportation 
tem development programmes, was not established.

Enormous funds are devoted to the development of the transportation system, so it is very important to ensure that mistakes do not occur whilst planning and establishing the underlying elements of the system, for Lithuania could suffer huge economic and social damage. Today the necessity appears to set the influence of separate changes as well as of their whole system on the social-economic characteristics of the infrastructure of the state.

Making evaluations, it was first accepted that the scope of capital investments into the development of the transportation system is directly related to the industry of the country, the increase of manufacturing agriculture, the arrangement of new manufacturing enterprises, the increase of transportation reach, traffic safety and other social-economic value. The reason for it is the improvement of transportation service. Therefore, each time the transit social-economic effect evaluation technique is used it should be corrected with respect to the specifics of the evaluating district, city or region, i.e. the arrangement of territorial social-manufacturing and cultural-economic objects, the scope of manufacturing and service spheres, population density and settlement distribution as well as multitude of other factors.

\section{Conclusions}

1.The analysis showed that the international market of transit transportation services is influenced by the infrastructure level of the country and transportation technologies applied, as these two indicators are responsible for the competitiveness of the state in the international market of transit services.

2. The transit cargo transportation must be analyzed as an integral object of scientific research.

3. The determinant factors of transit transportation are distinguished and can evaluate the efficiency of the transportation system of the country according to two aspects:

- general social-economic value, which can be direct and indirect;

- a negative effect caused by certain parts of the transportation system and the system itself.

4. In order to realize the intended aims relating to the development of the transit transportation system, general transit evaluation methodology should be established first of all.

\section{References}

1. Blumel, E. Managing and controlling growing harbors terminals. Fraunhofer Institute for Factory Operation and Automation. Magdeburg, 1994. $308 \mathrm{p}$.

2. Paulauskas, V. Logistic and development of harbors (Uostų vystymas ir logistika). Klaipèda, 1998. 162 p. (in Lithuanian).

3. Semenenko, A. Logistics of business (Предпринимательская логистика). Sankt-Peterburg: Politechnika, 1997. 349 p. (in Russian).

4. Pavone, G. Evaluation of transport services. World railways (Железные дороги мира), 1998, № 1, p. 23-30 (in Russian).

5. Palšaitis, R. Evaluation and regulation of transit transport influence on state social and economic characteristics. Transportas (Transport Engineering), No 1(14), 1997, p. 4- 8 (in Lithuanian).

6. Bazaras, D.; Palšaitis, R. Multimodal approach to the international transit transport. Transport, Vol XVIII, No 6, 2003, p. 248-254.

7. Case, K. E.; Fair, C. R. Principles of macroeconomics. New Jersey, 1994.

8. Baublys, A; Griškevičienè, D; Lazauskas, J.; Palšaitis, R. Transport economics (Transporto ekonomika). Vilnius: Technika, 2003. 477 p. (in Lithuanian).

9. Kasilingam, R. G. Logistics and transportation. London: Kluwer Academic Publishers, 1998.

10. McKinnon, A. C. Physical distribution systems. London: Routledge, 1998, p. 316.

11. Šakalys, A.; Lingaitis, P.; Palšaitis, R.; Jurkauskas, A.; Paulauskas, V.; Stankūnas, J.; Jarašūnienè, A. Strategy of Lithuania transport and transit development (Lietuvos transporto ir tranzito plètros strategija). Vilnius, 2002. 29 p. (in Lithuanian).

12. Palšaitis, R. Problems of transit and logistics development in Lithuania (Tranzito ir logistikos pletros problemos Lietuvoje). Vilnius, 2000, p. 118-129 (in Lithuanian).

13. Bazaras, D.; Palšaitis, R.; Labanauskas, G. The comparative analysis of Lithuanian and Latvian transit transport. Transport, Vol XIX, No 1, 2004, p. 9-14. 